\title{
Failure rates and functional results for intercalary femur reconstructions after tumour resection
}

\begin{abstract}
Albergo, J. I.
2020-04

Albergo , J I , Gaston , C L , Farfalli , G , Laitinen , M , Parry , M C , Ayerza , MA , Risk , M , Jeys , L M \& Aponte-Tinao , L 2020 , ' Failure rates and functional results for intercalary femur reconstructions after tumour resection ', Musculoskeletal surgery , vol. 104 , no. 1 , pp. 59-65 . https://doi.org/10.1007/s12306-019-00595-1
\end{abstract}

http://hdl.handle.net/10138/329524

https://doi.org/10.1007/s12306-019-00595-1

publishedVersion

Downloaded from Helda, University of Helsinki institutional repository.

This is an electronic reprint of the original article.

This reprint may differ from the original in pagination and typographic detail.

Please cite the original version. 


\title{
Failure rates and functional results for intercalary femur reconstructions after tumour resection
}

\author{
J. I. Albergo ${ }^{1} \cdot$ L. C. Gaston ${ }^{2}$ - G. L. Farfalli ${ }^{1} \cdot$ M. Laitinen ${ }^{2,3} \cdot$ M. Parry ${ }^{2} \cdot$ M. A. Ayerza ${ }^{1} \cdot$ M. Risk ${ }^{1} \cdot$ L. M. Jeys ${ }^{2}$. \\ L. A. Aponte-Tinao ${ }^{1}$
}

Received: 22 October 2018 / Accepted: 2 March 2019 / Published online: 8 March 2019

(c) Istituto Ortopedico Rizzoli 2019

\begin{abstract}
Purpose To compare the results for patients treated with intercalary endoprosthetic replacement (EPR) or intercalary allograft reconstruction for diaphyseal tumours of the femur in terms of: (1) reconstruction failure rates; (2) cause of failure; (3) risk of amputation of the limb; and (4) functional result.

Methods Patients with bone sarcomas of the femoral diaphysis, treated with en bloc resection and reconstructed with an intercalary EPR or allograft, were reviewed. A total of 107 patients were included in the study (36 EPR and 71 intercalary allograft reconstruction). No differences were found between the two groups in terms of follow-up, age, gender and the use of adjuvant chemotherapy.

Results The probability of failure for intercalary EPR was $36 \%$ at 5 years and $22 \%$ for allograft at 5 years $(p=0.26)$. Mechanical failures were the most prevalent in both types of reconstruction. Aseptic loosening and implant fracture are the main cause in the EPR group. For intercalary allograft reconstructions, fracture followed by nonunion was the most common complication. Ten-year risk of amputation after failure for both reconstructions was 3\%. There were no differences between the groups in terms of the mean Musculoskeletal Tumor Society score (27.4, range 16-30 vs. 27.6, range 17-30).

Conclusions We have demonstrated similar failure rates for both reconstructions. In both techniques, mechanical failure was the most common complication with a low rate of limb amputation and good functional results.

Level of evidence Level III, therapeutic study.
\end{abstract}

Keywords Bone sarcoma $\cdot$ Endoporsthesis $\cdot$ Allograft $\cdot$ Intercalary

\section{Introduction}

There has been an increase in the number of patients with malignant bone tumours treated with limb salvage surgery in the last three decades, largely due to advances in early diagnosis, accurate preoperative staging, orthopaedics expertise, and the evolution of implants [1-3]. Primary tumours of bone arising from the diaphyseal region of long bones represent a unique challenge for orthopaedic surgeons. This region does allow en bloc resection with epiphyseal 
preservation, that represents preservation of the joint above and below of the plan resection [4-8]. Different options of reconstruction for bone defect after massive tumour resections of the femur have been described in the literature and include biological reconstruction such as autogenous vascularized fibular grafts $[9,10]$, extracorporeal irradiated and reimplantation bone $[11,12]$, bone transportation or distraction osteogenesis $[13,14]$ and massive allograft $[4,6,15]$. Options for non-biological reconstruction include intercalary endoprosthetic replacements (EPR) $[1,4,16]$. Most common complications described for biological reconstruction include fracture, risk of infection and nonunion [10, 17-24]. Complications with endoprostetic reconstructions include aseptic loosening, infection and fracture of the prostheses $[1,2,4,16,25,26]$. The ideal method of reconstruction for diaphyseal segmental defects remains unclear.

The purpose of this study, therefore, was to compare two groups of patients treated with intercalary EPR or intercalary allograft reconstruction for diaphyseal femoral bone tumours and analyse: (1) reconstruction failure rates; (2) cause of failure; (3) risk of amputation of the limb; and (4) functional results measured with Musculoskeletal Society of Tumor Society (MSTS) scoring and time to full weight bearing.

\section{Materials and methods}

Patients were retrospectively identified from a prospectively maintained oncology database at each of the two contributory institutions. All patients with a primary tumour of bone arising from the femoral diaphysis treated by limb salvage resection and reconstruction, preserving both the proximal and distal joints between 1980 and 2014, were included. Two different oncology centres were involved in the study: Oncology Unit 1 specialized in endoprosthetic replacement for bone tumours (150 oncological megaprostheses per year) and Unit 2 specialized in allograft reconstruction (more than 800 massive allografts done). The inclusion criteria were: age below 60 years, diagnosis of bone sarcoma of the femur, minimum followup for patients alive of 24 months and treated with limb salvage reconstruction. Patients with soft tissue sarcomas and bone invasion or aggressive benign lesion were excluded. The study population comprised 107 patients, 36 in the EPR group, with a median age of 19 years (range $8-60$ ), and 71 in the allograft group, with a median age of 16 (range 6-55). The variety of histological indications for resection was equally represented in each group. The use of chemotherapy, either adjuvant or neoadjuvant, was not different between the two groups, nor was the duration of follow-up (Table 1). Complete data were available for all patients included in the study. Failure of the reconstruction was defined as revision of the prosthesis or allograft reconstruction for any cause. The method of treatment of these complications was also recorded, in particular, the necessity for limb removal. Failures of the reconstruction in both groups were defined according to the modified Henderson classification for limb salvage reconstruction is divided into six types. Type 1 failure is defined as soft tissue failure (1A: failure of function/1B: failure of cover; type 2, aseptic loosening (in the case of EPR, $2 \mathrm{~A}$ : early $<2$ years after implantation/2B: late $>2$ years after implantation) or graft-host nonunion for allografts (2A: hypertrophic nonunion/2B: atrophic nonunion); type 3, structural failure (3A: implant or fixation/3B: bone or graft); type 4, infection (4A: early/4B: late), and type 5, tumour progression (5A: soft tissue/5B: bone). In the modified classification, type 6 , paediatric failures are defined as $6 \mathrm{~A}$, growth arrest resulting in longitudinal or angular deformity, or 6B, the formation of a dysplastic joint [26].
Table 1 Demographic characteristics of the 107 patients of the series

\begin{tabular}{|c|c|c|c|}
\hline & Endoprostheses & Intercalary allograft & $p$ value \\
\hline Age (median years) & 19, IQR 24 , range $8-60$ & 16, IQR 12 , range $6-55$ & 0.14 \\
\hline Gender (\%) & $\begin{array}{l}23 \text { males }(64 \%) \\
13 \text { female }(36 \%)\end{array}$ & $\begin{array}{l}45 \text { males }(63 \%) \\
26 \text { females }(37 \%)\end{array}$ & 0.90 \\
\hline \multirow[t]{4}{*}{ Type of tumour $(n)$} & Osteosarcoma: 13 & Osteosarcoma: 44 & - \\
\hline & Chondrosarcoma: 1 & Chondrosarcoma: 8 & - \\
\hline & Ewing Sarcoma: 17 & Ewing sarcoma: 16 & - \\
\hline & Other ${ }^{\mathrm{a}}: 5$ & Other': 3 & - \\
\hline Chemotherapy (\%) & $32(89 \%)$ & $63(89 \%)$ & 0.58 \\
\hline Resection length (median $\mathrm{cm}$ ) & 12 , IQR 5.5, range 5-30 & 16, IQR 8 , range 7-29 & 0.12 \\
\hline Median follow-up in months & 114, IQR 189 , range $10-411$ & 129, IQR 110 , range $12-311$ & 0.72 \\
\hline 10 -year overall survival & $71 \%$ (95\% CI 54-87\%) & $80 \%$ (95\% CI 70-89\%) & 0.46 \\
\hline
\end{tabular}

$I Q R$ interquartile range

${ }^{\mathrm{a}} \mathrm{MFH}$, leiomyosarcoma (2), adamantinoma, Spindle cell sarcoma

${ }^{\mathrm{b}}$ Fibrosarcoma, Spindle cell sarcoma 
The functional assessment following limb salvage was performed using the revised 30-point functional classification system established by the MSTS and time for full weight bearing recorded from the reports [27].

All allografts used for bone reconstructions were nonirradiated, harvested under sterile conditions and stored frozen in the bone bank at one of the study institution. All bacteriologic and viral tests available at the time were performed in accordance with the recommendations of the American Association of Tissue Banks [28]. Between 1980 and 2008, allografts were selected according preoperative image studies (X-rays and CT scan) and in the last years through the 3D virtual bone banking [29] (Fig. 1).

All of the prostheses were custom made, designed and manufactured at the Department of Biomedical Engineering of the Institute of Orthopaedics of University College, London (now known as Stanmore Implants Worldwide, Royal National Orthopaedic Hospital Trust, Stanmore, Middlesex). All the implants used in this series had cement fixation [30]. All the operations were performed in a clean-air operation room. Resection of the tumour was carried out following oncological principles, endeavouring to achieve a wide margin of resection (Fig. 2).

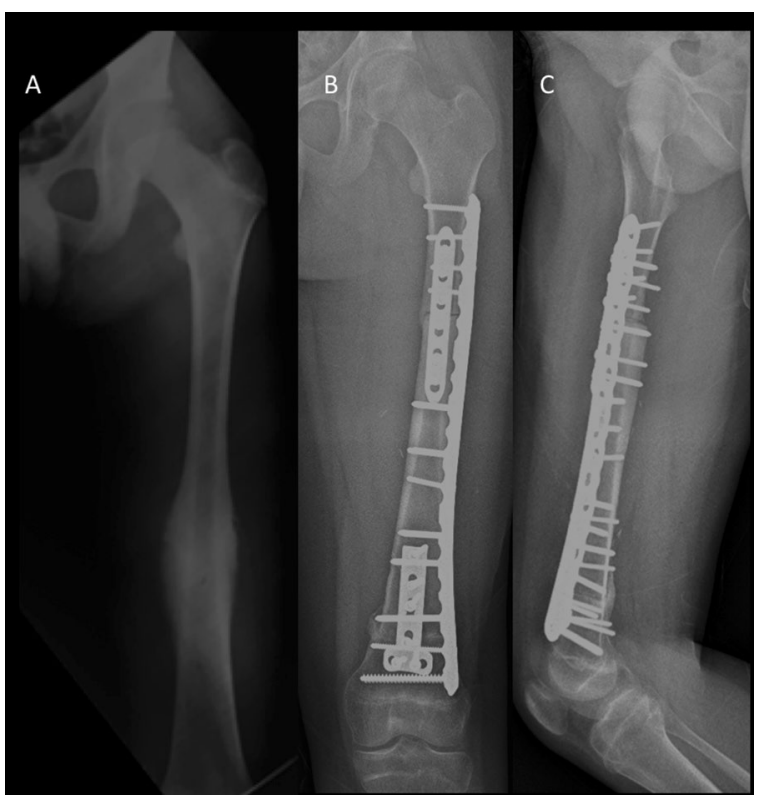

Fig. 1 Fourteen-year-old male with a periosteal osteosarcoma of the femur treated with an allograft Intercalary femur reconstruction. a AP X-ray of the femur that shows a bone lesion in the mid shaft with periosteal reaction (sunrise). b, $\mathbf{c} 1$-year post-operative AP and lateral $\mathrm{X}$-rays with an intercalary allograft reconstruction stabilized with rigid fixation, a long 4.5 LCP lateral and two compressive plates anterior in both osteotomies

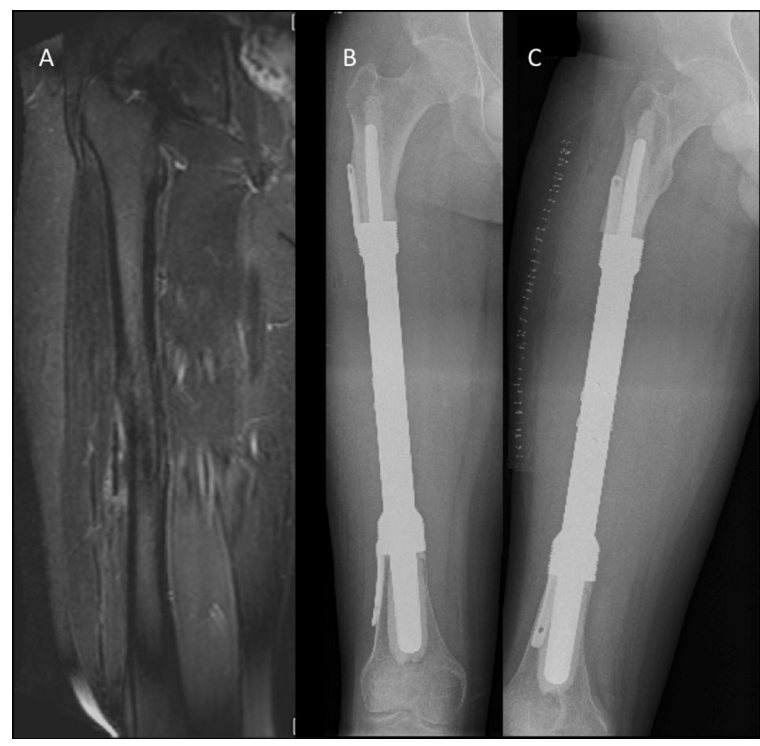

Fig. 2 Twenty-two-year-old male with an Ewing sarcoma of the left femur. a Preoperative coronal MRI views showing the mid shaft invasion and soft tissue extension of the tumour. b, c Post-operative AP and lateral X-rays views of the intercalary EPR reconstruction after tumour resection

\section{Statistical analysis}

Demographic differences between groups were assessed using the Wilcoxon test for nonparametric variables and for continuous variables. For categorical variables, a Chi-square test was used. The reconstruction failure rates were calculated by a competitive risk analysis method with limb salvage reconstruction censored at the time of failure or last follow-up and death as the competing risk. Differences between groups were compared by log-rank test. To estimate patients' overall survival, the Kaplan-Meier method was used. The statistical analysis was performed using the $\mathrm{R}$ programming language (R Foundation for Statistical Computing, Vienna, Austria). Statistical significance was defined as $p<0.05$ [31].

\section{Results}

The overall survival (OS) rate at 5 and 10 years for the entire series was $84 \%$ [95\% confidence interval (95\% CI) 77-91\%] and 76\% (95\% CI 67-84\%). Survival analysis per group showed for EPR reconstruction an OS of $86 \%$ (95\% CI $75-97 \%)$ at 5 years and $71 \%(95 \%$ CI $54-87 \%)$ at 10 years. For allograft group, the OS at 5 and 10 years was $82 \%$ (95\% CI 72-91\%) and 80\% (95\% CI 70-89\%), respectively. No statistical differences between both groups were found $(p=0.46)$.

The overall risk of reconstruction failure, as analysed according to a competing risk method for the study 
population as a whole, was 36\% (95\% CI 18-55\%) at 5 years and $50 \%$ (95\% CI 29-71\%) at 10 years for intercalary EPR and $22 \%(95 \% \mathrm{CI} 12-33 \%)$ at 5 years and $39 \%(95 \% \mathrm{CI}$ $25-53 \%$ ) at 10 years for intercalary allografts (Fig. 3), respectively. This risk of reconstruction failure was not statistically different between the reconstruction methods at 5 years post-primary procedure $(p=0.270)$ or 10 years post-primary procedure ( $p=0.162)$ (Fig. 3).

The mode of failure, defined by the modified Henderson classification, is summarized in Table 2. In the EPR group, 18 out of $36(50 \%)$ patients developed a failure at some stage during the follow-up period. Aseptic loosening (type 2) and implant fracture (type 3 ) were the most common mechanical

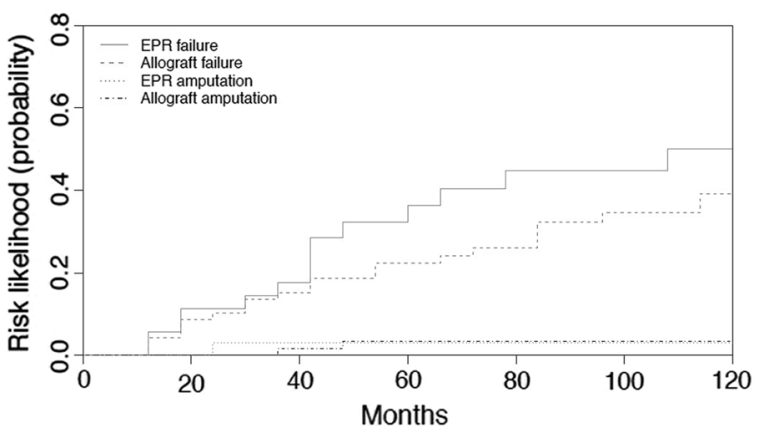

Fig. 3 Competitive risk analysis for reconstruction failure and risk of amputation. EPR endoprosthestic replacement failures occurring in 16 out of 18 patients (89\%). The other two failures were defined as: one infection (type 4) and one local recurrence (type 5). Sixteen patients with a mechanical failure were revised to a new prosthesis. Six out of the 16 patients were revised with a new intercalary EPR, while the other 10 patients need to be reconstructed with a distal femur EPR (n: 6) or a proximal femur EPR (n: 4). The patient with infection failure was treated with a two-stage revision and finally reconverted to a distal femur EPR, while the patient that presented with a local recurrence failure was finally treated with an amputation.

In 25 out of $71(35 \%)$ patients in the intercalary allograft group, a failure was seen. In 21 out of 25 (84\%), this was defined as a mechanical failure (type 2 or 3 ), with the remaining four failures attributable to infection (type 4) in 1 out of 25 , tumour progression (type 5) in 2 out of 25 , and growth arrest (type 6A) occurring in 1 out of 25 patients. Seventeen patients that presented an allograft fracture (type 3) needed to be revised: One patient was treated with a vascular fibula and new osteosynthesis achieving consolidation; in 11 patients, revision surgery included a new intercalary allograft and in five cases the revision was done with a distal femur endoprostetic. In the four patients with nonunion (type 2 ), the osteosynthesis was changed from one lateral plate to two plates $\left(90^{\circ}\right.$ conformation) + bone autograft with the iliac crest in the nonunion site being done with final consolidation. The patient who suffered an infection was treated with
Table 2 Modified Henderson classification for limb salvage reconstruction failure

\begin{tabular}{llll}
\hline Failures & & $\begin{array}{l}\text { Endoprosthetic recon- } \\
\text { struction }(n=36)\end{array}$ & $\begin{array}{l}\text { Intercalary } \\
\text { allograft } \\
(n=71)\end{array}$ \\
\hline Total failures & & $18(50 \%)$ & $25(35 \%)$ \\
Overall mechanical failures (\%) & & $16(44 \%)$ & $21(29.5 \%)$ \\
Henderson type 1 & A & 0 & 0 \\
(Soft tissue failure) & B & 0 & 0 \\
Henderson type 2 & A & 3 & 3 \\
(Aseptic loosening or graft-host nonunion & B & 9 & 1 \\
Henderson type 3 & A & 4 & 0 \\
(Structural failure) & B & 0 & 17 \\
Overall non-mechanical failures & & $2(6 \%)$ & $4(5.5 \%)$ \\
Henderson type 4 & A & 0 & 1 \\
(Infection) & B & 1 & 0 \\
Henderson type 5 & A & 1 & 0 \\
(Tumour progression) & B & 0 & 1 \\
Henderson type 6 & A & 0 & 0 \\
(Paediatric failures) & B & 0 & 2 \\
\hline
\end{tabular}

Henderson et al. classification: type $1-$ soft tissue failures (1A: failure of function/1B: failure of cover. Type 2: aseptic loosening for endoprosthetics $(2 \mathrm{~A}$ : early $<2$ years after implantation/2B: late $>2$ years after implantation) or graft-host nonunion for allografts (2A: hypertrophic nonunion/2B: atrophic nonunion). Type 3: structural failure (3A: implant or fixation/3B: bone or graft). Type 4: infection (4A: early $<2$ years after implantation/4B: late $>2$ years after implantation). Type 5: tumour progression (5A: soft tissue/5B: bone). Type 6: paediatric failures (6A: growth arrest resulting in longitudinal or angular deformity/6B: dysplastic joint 
a two-stage revision and was finally reconstructed with distal femur endoprostheses. Two patients developed local tumour progression: one patient was treated with resection and a new allograft reconstruction, and the other patient received a limb amputation.

The overall rate of limb salvage following intercalary resection and reconstruction was comparable between the groups with a risk of amputation after failure of reconstruction within 10 years of 3\% (95\% CI 0-9\%) for the EPR group, and 3\% (95\% CI 0-8\%) for the allograft group $(p=0.998)$.

The functional results, measured by the MSTS score, demonstrated no difference between the two groups with a median, MSTS score of 27 (range 16-30) in the EPR group, and a median score of 28 (range 17-30) in the allograft group. Time to full weight bearing was significantly shorter in the EPR group with a median time of 3 weeks (range 1-6) compared to 22 weeks (range 17-49) for the patients with an allograft intercalary reconstructions $(p<0.001)$.

\section{Discussion}

Several options for intercalary reconstruction following tumour resection, including biological and prosthetic options, have been described and benefits, and complications unique to each reconstruction method have been reported $[1-10,15-19,25,26]$. In this study, we present the results from a comparative study between two high-volume oncology units treating patients with primary malignant bone tumours of the femur with resection and reconstruction and limb salvage surgery either by intercalary EPR or allograft.

One of the first series about intercalary prostheses was presented by Abudu et al. reporting 18 patients (including 13 femoral reconstructions) and concluded that EPR after excision of diaphyseal tumours offers good oncological and functional outcome, being symptomatic mechanical loosening the most common complication (6/10) [4]. In concordance with Birmingham results, Hanna et al. reported an $85 \%$ overall survival at 5 years for intercalary femur endoprostheses reconstructions. The rate of revision of the series was $22 \%$, and the overall rate of re-operation was $26 \%$ [25]. Recently, Benevenia et al. [1] analysed a series of patients that received intercalary implants for primary and metastatic bone tumours and found that patients, treated with intercalary endoprostheses in the femur, experienced more frequent complications than those treated for lesions in other long bones.

A multicentre study from the Netherlands analysed intercalary allograft reconstructions and reported high complication rates, with mechanical complications being the most prevalent (nonunion $40 \%$ and fracture 29\%) [15]. These results are in agreement with our findings. Aponte et al. in
2012 reviewed 83 patients (some of them included in this series) who underwent an intercalary femoral segmental allograft reconstruction and reported that allograft fracture remained a major problem. The incidence of fracture in this series was $17 \%$, and his group found no association between fracture and the type of osteosynthesis [5]. According to the literature, femoral intercalary allograft seems to have a higher risk of mechanical failure when compared to other long bones [15, 17-20]. The use of intramedullary cement as augmentation for intercalary allograft reconstruction has been reported by Gupta et al. as a reliable option to reduce fracture risk [32]. Also, the use of intramedullary nails to augment fixation, the length of the resection and the site of the osteotomy (diaphyseal versus metaphyseal) have been described as negative prognostic factors for failure of the reconstruction $[5,18]$.

Alternative reconstruction options for diaphsyeal tumours of the femur include: fibula grafting, with a reported failure rate around $20-25 \%$ being fracture (30-50\%) and nonunion (15-25\%) the most common complications reported $[10,20-22]$. Fibula grafting is a viable option to improve the rate of union or to rescue mechanical failures following non-vascularized biological reconstruction $[5,17,33$, 34]. A combination of allograft + vascularized fibula has been used for intercalary reconstructions of the femur with good results. In particular, the biologic properties of the fibula were seen to promote allograft fracture healing after hardware replacement and to decrease the long-term risk of mechanical complication [33].

Extracorporeal irradiation and autograft reimplantation is another acceptable biological alternative for the reconstruction of the diaphysis of the femur, with a major existing disadvantage, the absence of material for histopathological examination of the effect of chemotherapy and the determination of surgical resection margins [11, 12]. Distraction osteogenesis should be considered as an alternative reconstruction technique for limb salvage surgery after diaphyseal tumour resection with acceptable results being reported, but should not be considered for massive bone defects (more than $15 \mathrm{~cm})[13,14]$.

Although infections have been described as a major concern in massive allograft and modular endoprostheses, in our series, infection was not reported as a common complication for either of the two reconstruction techniques. Mechanical complications were the most frequent cause of failure in diaphyseal femoral reconstruction after bone sarcoma resections (Table 2). We know that the aim of intercalary reconstruction is to preserve the proximal and distal joint, but eventually, after failure revision, there could be a need to remove a joint. We reported joint replacement after revision surgery in $30.5 \%$ of EPR and $8.4 \%$ of intercalary allografts.

Intercalary reconstructions, in general, provide good functional results, attributable to the preservation of both 
proximal and distal joints (Table 2). Good functional results, early mobilization and early weight bearing are benefits described for intercalary EPR of the femoral diaphysis [1, 4]. In contrast, biological reconstruction requires a lengthy period of non-weight bearing to allow for union and graft hypertrophy $[5,6,15]$. However, biological reconstructions allow the opportunity to restore bone stock after massive resection, which is a significant advantage, particularly in the paediatric and young patients population [23, 24, 35].

We acknowledge certain limitations with this study. Firstly, we recognize the retrospective design. Secondly, the selection bias for the patients who were treated in two different countries by two different groups. Thirdly, the period of study includes many decades that may result in patients with failing implants not being known to the treating centre. Fourthly, the group has some inherent heterogeneity in terms of diagnosis, the amount of soft tissue resection, the method of internal fixation in the allograft group and length of bone resection, which could affect the incidence of failures, complications and functional outcomes.

We have demonstrated the durability of both the reconstruction options studied: intercalary allograft and intercalary EPR. Both result in good implant survival, with a failure rate of $22 \%$ and $36 \%$ at 5 years. The benefits of intercalary allograft reconstruction include the restoration of bone stock and therefore should be considered in younger patients. Intercalary EPR allows early weight bearing and therefore should be considered for those in whom this is a priority. In both techniques, mechanical failure was the most common complication; however, the amputation rate was low in both groups.

\section{Compliance with ethical standards}

Conflict of interest On behalf of all authors, the corresponding author states that there is no conflict of interest.

Ethical approval This article does not contain any studies with human participants or animals performed by any of the authors.

\section{References}

1. Benevenia J, Kirchner R, Patterson F, Beebe K, Wirtz DC, Rivero S, Palma M, Friedrich MJ (2016) Outcomes of a modular intercalary endoprosthesis as treatment for segmental defects of the femur, tibia, and humerus. Clin Orthop Relat Res 474(2):539-548

2. Jeys LM, Kulkarni A, Grimer RJ, Carter SR, Tillman RM, Abudu A (2008) Endoprosthetic reconstruction for the treatment of musculoskeletal tumors of the appendicular skeleton and pelvis. J Bone Jt Surg Am 90(6):1265-1271

3. Mankin HJ, Doppelt SH, Sullivan TR, Tomford WW (1982) Osteoarticular and intercalary allograft transplantation in the management of malignant tumors of bone. Cancer 15(50):613-630
4. Abudu A, Carter SR, Grimer RJ (1996) The outcome and functional results of diaphyseal endoprostheses after tumour excision. J Bone Jt Surg Br 78:652-657

5. Aponte-Tinao L, Farfalli GL, Ritacco LE, Ayerza MA, Muscolo DL (2012) Intercalary femur allografts are an acceptable alternative after tumor resection. Clin Orthop Relat Res 470(3):728-734

6. Donati D, Capanna R, Campanacci D, Del Ben M, Ercolani C, Masetti C, Taminiau A, Exner GU, Dubousset JF, Paitout D et al (1993) The use of massive bone allografts for intercalary reconstruction and arthrodeses after tumor resection. A multicentric European study. Chir Organi Mov 78(2):81-94

7. Muscolo DL, Ayerza MA, Aponte-Tinao L, Ranalletta M, Abalo E (2004) Intercalary femur and tibia segmental allografts provide an acceptable alternative in reconstructing tumor resections. Clin Orthop Relat Res 426:97-102

8. Ortiz-Cruz EJ, Gebhardt MC, Jennings LC, Springfield DS, Mankin HJ (1997) The results of transplantation of intercalary allografts after resection of tumors: a long-term follow-up study. J Bone Jt Surg Am 79:97-106

9. Ceruso M, Falcone C, Innocenti M, Delcroix L, Capanna R, Manfrini M (2001) Skeletal reconstruction with a free vascularized fibula graft associated to bone allograft after resection of malignant bone tumor of limbs. Handchir Mikrochir Plast Chir 33:277-282

10. Chang DW, Weber KL (2005) Use of a vascularized fibula bone flap and intercalary allograft for diaphyseal reconstruction after resection of primary extremity bone sarcomas. Plast Reconstr Surg 116:1918-1925

11. Krieg AH, Davidson AW, Stalley PD (2007) Intercalary femoral reconstruction with extracorporeal irradiated autogenous bone graft in limb-salvage surgery. J Bone Jt Surg Br 89(3):366-371

12. Nakamura T, Abudu A, Grimer RJ, Carter SR, Jeys L, Tillman RM (2013) The clinical outcomes of extracorporeal irradiated and re-implanted cemented autologous bone graft of femoral diaphysis after tumour resection. Int Orthop 37(4):647-651

13. Cañadell J, Forriol F, Cara JA (1994) Removal of metaphyseal bone tumours with preservation of the epiphysis: physeal distraction before excision. J Bone Jt Surg Br 76:127-132

14. Tsuchiya H, Tomita K, Minematsu K, Mori Y, Asada N, Kitano S (1997) Limb salvage using distraction osteogenesis: a classification of the technique. J Bone Jt Surg Br 79:403-411

15. Bus MP, Dijkstra PD, van de Sande MA, Taminiau AH, Schreuder HW, Jutte PC, van der Geest IC, Schaap GR, Bramer JA (2014) Intercalary allograft reconstructions following resection of primary bone tumors: a nationwide multicenter study. J Bone Jt Surg Am 96(4):e26. https://doi.org/10.2106/JBJS.M.00655

16. Aldlyami E, Abudu A, Grimer RJ, Carter SR, Tillman RM (2005) Endoprosthetic replacement of diaphyseal bone defects. Longterm results. Int Orthop 29(1):25-29

17. Aponte-Tinao LA, Ayerza MA, Muscolo DL, Farfalli GL (2015) Should fractures in massive intercalary bone allografts of the lower limb be treated with ORIF or with a new allograft? Clin Orthop Relat Res 473(3):805-811

18. Frisoni T, Cevolani L, Giorgini A, Dozza B, Donati DM (2012) Factors affecting outcome of massive intercalary bone allografts in the treatment of tumours of the femur. J Bone Jt Surg Br 94(6):836-841

19. Thompson RC, Pickvance EA, Garry D (1993) Fractures in large segment allografts. J Bone Jt Surg Am 75:1663-1673

20. Moran SL, Shin AY, Bishop AT (2006) The use of massive bone allograft with intramedullary free fibular flap for limb salvage in a pediatric and adolescent population. Plast Reconstr Surg 118:413-419

21. Hsu RW, Wood M, Sim FH, Chao EY (1997) Free vascularized fibular grafting for reconstruction after tumour resection. J Bone Jt Surg Br 79:36-42 
22. Zaretski A, Amir A, Meller I, Leshem D, Kollender Y, Barnea Y, Bickels J, Shpitzer T, Ad-El D, Gur E (2004) Free fibula long bone reconstruction in orthopedic oncology: a surgical algorithm for reconstructive options. Plast Reconstr Surg 113:1989-2000

23. Muscolo DL, Ayerza MA, Aponte-Tinao L, Farfalli G (2008) Allograft reconstruction after sarcoma resection in children younger than 10 years old. Clin Orthop Relat Res 466:1856-1862

24. Muscolo DL, Ayerza MA, Aponte-Tinao LA (2006) Massive allograft use in orthopedic oncology. Orthop Clin North Am 37:65-74

25. Hanna SA, Sewell MD, Aston WJ, Pollock RC, Skinner JA, Cannon SR, Briggs TW (2010) Femoral diaphyseal endoprosthetic reconstruction after segmental resection of primary bonetumours. J Bone Jt Surg Br 92(6):867-874

26. Henderson ER, O'Connor MI, Ruggieri P, Windhager R, Funovics PT, Gibbons CL, Guo W, Hornicek FJ, Temple HT, Letson GD (2014) Classification of failure of limb salvage after reconstructive surgery for bone tumors: a modified system including biological and expandable reconstructions. Bone Jt J 96:1436-1440

27. Enneking WF, Dunham W, Gebhardt MC, Malawar M, Pritchard DJ (1993) A system for the functional evaluation of reconstructive procedures after surgical treatment of the musculoskeletal system. Clin Orthop Relat Res 286:241-246

28. Albergo JI, Gaston CL, Aponte-Tinao LA, Ayerza MA, Muscolo DL, Farfalli GL, Jeys LM, Carter SR, Tillman RM, Abudu AT, Grimer RJ (2017) Proximal tibia reconstruction after bone tumor resection: are survivorship and outcomes of endoprosthetic replacement and osteoarticular allograft similar? Clin Orthop Relat Res 475(3):676-682

29. Ritacco LE, Farfalli GL, Milano FE, Ayerza MA, Muscolo DL, Aponte-Tinao L (2013) Validity of an automatic measure protocol in distal femur for allograft selection from a three-dimensional virtual bone bank system. Cell Tissue Bank 14(2):213-220
30. Myers GJ, Abudu AT, Carter SR, Tillman RM, Grimer RJ (2007) The long-term results of endoprosthetic replacement of the proximal tibia for bone tumors. J Bone Jt Surg Br. 89:1632-1637

31. R Core Team (2014) R: a language and environment for statistical computing. Vienna, Austria. http://www.Rproject.org. Accessed Aug 2016

32. Gupta S, Kafchinski LA, Gundle KR, Saidi K, Griffin AM, Wunder JS, Ferguson PC (2017) Intercalary allograft augmented with intramedullary cement and plate fixation is a reliable solution after resection of a diaphyseal tumour. Bone Jt J 299-B(7):973-978

33. Campanacci DA, Totti F, Puccini S, Beltrami G, Scoccianti G, Del Croix L, Innocenti M, Capanna R (2018) Intercalary reconstruction of femur after tumour resection: is a vascularized fibular autograft plus allograft a long-lasting solution? Bone Jt J 100-B(3):378-386

34. Campanacci DA, Puccini S, Caff G, Beltrami G, Piccioli A, Innocenti M, Capanna R (2014) Vascularized fibular grafts as a salvage procedure in failed intercalary reconstructions after bone tumor resection of the femur. Injury 45(2):399-404

35. San-Julian M, Dolz R, Garcia-Barrecheguren E, Noain E, Sierrasesumaga L, Cañadell J (2003) Limb salvage in bone sarcomas in patients younger than age 10: a 20-year experience. J Pediatr Orthop 23:753-762

Publisher's Note Springer Nature remains neutral with regard to jurisdictional claims in published maps and institutional affiliations. 